Original Research Paper

\title{
Characterization and Evaluation of Charcoal Briquettes Using Banana Peel and Banana Bunch Waste for Household Heating
}

\author{
Sumrit Mopoung and Vijitr Udeye \\ Department of Chemistry, Faculty of Science, Naresuan University, Phitsanulok, Thailand
}

\author{
Article history \\ Received: 13-10-2015 \\ Revised: 07-01-2016 \\ Accepted: 15-10-2016
}

Corresponding Author:

Sumrit Mopoung

Department of Chemistry, Faculty

of Science, Naresuan University,

Phitsanulok, Thailand

Email:sumritm@nu.ac.th

\begin{abstract}
The charcoal briquettes from banana peel and banana bunch wastes from dried banana industry for household heating were characterized and evaluated. A $200 \mathrm{~L}$ pyrolyzer was used for charcoal and wood vinegar production at $350^{\circ} \mathrm{C}$ pyrolysis temperature. The percent yield of charcoal and wood vinegar were determined. The effects of clay binder $(0-15 \% \mathrm{w} / \mathrm{w})$ on the properties of charcoal briquettes such as ash content, hardness, combustion calorific value, emissions data, burn time and combustion efficiency were evaluated. It was found that the percent yields of charcoal and wood vinegar from pyrolysis of banana peel and banana bunch are $57 \%, 7.53 \%$ and $58.6 \%, 6.76 \%$, respectively. The banana bunch charcoal retained some functional groups to a higher degree than the banana peel charcoal. These include $-\mathrm{OH}, \mathrm{C}=\mathrm{O}, \mathrm{C}=\mathrm{C}, \mathrm{C}-\mathrm{H}$ and $\mathrm{C}-\mathrm{C}$ groups. The porous shapes of banana peel charcoal and banana bunch charcoal are honeycomb and tube structure, respectively. The calorific value of both charcoal briquettes decreased with increasing ratios of clay and ash content. The values range from $5,115.51$ to $6,396.66 \mathrm{cal} \mathrm{g}^{-1}$. The hardness obtained with $5 \%$ clay binder is $23.31 \mathrm{~kg}$ and $25.90 \mathrm{~kg}$ for banana peel charcoal briquette and banana bunch charcoal briquette, respectively. Both charcoal briquettes containing $5 \%$ clay are smokeless during combustion and result in red-brown ash after combustion. The dust and total $\mathrm{CO}$ emissions of banana peel charcoal briquette and banana bunch charcoal briquette during combustion are $15.38 \mu \mathrm{g} \mathrm{m}^{-3}$ and 3463 $\mathrm{ppm}$ and $11.97 \mu \mathrm{g} \mathrm{m}^{-3}$ and $1568 \mathrm{ppm}$, respectively. The maximum temperatures of water are 88 and $84^{\circ} \mathrm{C}$ and times needed to reach the maximum temperatures were 36 and $48 \mathrm{~min}$ for banana peel charcoal briquette and banana bunch charcoal briquette combustion, respectively. The maximum burning times and combustion efficiencies are $114 \mathrm{~min}$ and $9.10 \%$ and $92 \mathrm{~min}$ and $8.38 \%$ for banana peel charcoal briquette and banana bunch charcoal briquette, respectively.
\end{abstract}

Keywords: Charcoal Briquette, Wood Vinegar, Banana Peel, Banana Bunch, Households

\section{Introduction}

Charcoal and firewood are among the primary cooking fuels used in many developing countries, even though they both pose a number of environmental, social and economic challenges. Including the ecological impacts of indoor air pollution produced by cooking with solid fuels (Gladstone et al., 2014). Charcoal is an impure form of graphitic carbon obtained as a residue when carbonaceous material is partially burned with limited access of air. This process rapidly decomposes organic material through anaerobic heating by smoldering agricultural waste (i.e., covering burning biomass with soil) in pits or trenches (Claxton, 2014). The process of fuel combustion involves: (1) Water evaporation required to evaporate the moisture in fuel; 
(2) distillation and combustion of volatile organic matter with oxygen producing heat; and (3) combustion of the fixed carbon at a high temperature (Claxton, 2014). However, oxidation of fuel is not always complete and small amounts of carbon monoxide, hydrocarbons and other gases, such as nitrogen/sulfur oxides and fumes are also released. Some of these are harmful to health, some to the environment and some to the atmosphere. Pollutants such as carbon monoxide, sulfur dioxide, nitrogen dioxide and particulate matter are of significance because of the effect they have on the environment and human health (Yazdani et al., 2012). The factors that affect the amount and composition of pollutants released during fuel combustion include burn rate, fuel type, the type of combustion appliance and moisture content of the fuel (Claxton, 2014).

Agro-industrial biomass comprised of lignocellulosic waste is an inexpensive, renewable, abundant source of fuel material, which provides a unique natural resource for large-scale and cost-effective bio-energy collection. Lignocellulosic materials including agricultural wastes, forestry residues, grasses and woody materials have great potential for bio-fuel production. All plant materials are mostly composed of about 10-25\% lignin, 20-30\% hemicellulose and 40-50\% cellulose (Anwar et al., 2014). However, low density of biomass results in handling problems. Therefore, the aim of densification methods is to increase biomass density and in turn its calorific per unit of volume (Kusumaningrum and Munawar, 2014). Biopellet is an alternative energy that can substitute low grade coal using biomass sources. Bio-pellet from biomass sources has environmental advantages over coal. Several aspects such as moisture content, particle size and chemical compound, particularly lignin, content can influence bio-pellet properties. The advantages of bio-pellet include uniformity, high compressive strength and higher calorific value than its raw materials (Kusumaningrum and Munawar, 2014). Charcoals have been also transformed into briquettes for ease of handling and to reduce the dust problem and increase the energy density (Sjlie, 2012). Briquette charcoal is a solid fuel from organic matter containing carbon, which has a high calorific value and can be lit for a long time (Nuriana et al., 2014). There are clear advantages of charcoal briquettes that include price, burn time, environmental sustainability and potential for product standardization (Mwampamba et al., 2013). Wood charcoal briquettes have also been produced for their global warming reduction potential (Rousset et al., 2011) and are also financially and economically viable (Onaji and Siemons, 1993).

Nonindustrial charcoal production generates large emissions of greenhouse gases in the form of $\mathrm{CO}_{2}$ from forest degradation and methane from oxidation in traditional kilns, which are used by more than half of the households with very incomplete combustion and typically offering about 15\% efficiency (Sjlie, 2012). More than $90 \%$ of $\mathrm{CO}_{2}$ emissions are due to biomass conversion to charcoal. Roughly $3.9660 \mathrm{Kg}$ of $\mathrm{CO}_{2}$ emitted per $1 \mathrm{~kg}$ of charcoal produced. $\mathrm{CO}_{2}$ emissions throughout the charcoal production process are totally compensated for the environmental quality of the raw materials used (Rousset et al., 2011). Lignocellulosic materials (i.e., hazelnut shells) have been converted to charcoal, liquid and gaseous products (Demirbaş, 1999). This process can reduce gas emissions by converted them into liquid smoke or wood vinegar. Wood vinegar is produced when smoke from charcoal production is cooled by outside air while passing through a chimney. The cooling effect causes condensation of pyroligneous liquor, particularly when the temperature of smoke produced by carbonization ranges between 80 and $180^{\circ} \mathrm{C}$. This temperature is reached at the carbonization stage of exothermic decomposition and is indicated by the production of yellowish, acrid smoke (Burnette, 2010). Wood vinegar mainly consists of phenolic compounds and acetic acid. Wood vinegar can be used for many purposes. For instance, phenolic components, such as phenol, guaicol and cresol can act as biocidal agents with antifungal properties. The acetic acid functions as termiticidal agent. The 2-propanone and 1hydroxy-derivatives is value-added product for the synthesis of pharmaceuticals (Oramahi and Diba, 2013).

Banana peel is another type of agricultural, waste which originates from industrial banana production. Banana is one of the most popular tropical fruits consumed worldwide. In Thailand, 200 tons of banana peel is produced daily and the amount is constantly increasing. A small fraction of the peel is used for animal feed and the remainder becomes rotted garbage. Banana peel is carbohydrate rich and could, potentially, be converted into bioenergy (Nathoa et al., 2014). Banana waste contains $14 \%$ lignin, $14.8 \%$ hemicellulose and $13.2 \%$ cellulose (Anwar et al., 2014). It has the potential for industrial charcoal production for domestic use.

Cassava four (Teixeira et al., 2010), low density polyethylene (Massaro et al., 2014), pyrolytic oil and tar (Demirbaş, 1999) have been used as binders for the production of charcoal briquettes. These binders can increase the density, mechanical resistance, calorific value, flowability, durability, hardness and moisture resistance of charcoal briquettes (Jezerska et al., 2014). However, these compounds also generate smoke while burning due to the highly volatile matter contained in them. Clay is kaolinite type material. It has high chemical stability, low expansion coefficient, high hardness and strong layers (Mopoung et al., 2014). It is expected to be suitable as a binder for the production of smokeless charcoal briquettes. 
This research focuses on charcoal briquette production from banana peel and banana bunch wastes that may be an economically and ecologically viable substitute for other fuel types in domestic use. The raw materials were converted to charcoal and wood vinegar by a pyrolysis process. The aim of this process is to reduce the gas and smoke emissions into the environment. The charcoal and wood vinegar production by a 200-liter-vertical-oil-drum kiln were studied for percent yield. The charcoal was characterized by SEM, FTIR and approximate analysis. Clay was used as a binder, as it is abundant in nature and inexpensive, for the reduction of the emissions ( $\mathrm{CO}$, dust and smoke) and to increase hardness and burn time of the briquettes. The charcoal briquettes were analysed for thermal and mechanical properties using standard techniques including hardness testing, bomb calorimetry and combustion testing to improve environmental conditions of communities using traditional heating sources.

\section{Materials and Methods}

\section{Materials}

Materials used in this study are the banana peel and banana bunch wastes, which were obtained from Kong Krailat district, Sukhothai province, Thailand. These materials contain $88.2 \pm 0.1 \%$ moisture, $1.8 \pm 0.1 \%$ ash, $9.8+0.1 \%$ volatile matter and $1.9+0.0$ fixed carbon for banana peel and $92.9 \pm 0.5 \%$ moisture, $0.8 \pm 0.1 \%$ ash, $5.1 \pm 0.0 \%$ volatile matter and $1.4+0.1$ fixed carbon for banana bunch (Mopoung, 2005). Clay is a binder agent. It is composed of a tetrahedral $\mathrm{SiO}_{4}$ sheet and an octahedral sheet containing $\mathrm{Al}^{3+}$ ions (Rao et al., 2011).

\section{Pyrolyzer}

A 200-liter-vertical-oil-drum kiln (Fig. 1) was used for pyrolysis of banana peel and banana bunch. It consists of a door $(22.5 \times 22.5 \mathrm{~cm})$ located towards the bottom to allow the controlled inflow of the primary air that allows the fire to ignite and grow. The pyrolyzer contains three chimneys $(6 \mathrm{~cm}$ in diameter and $75 \mathrm{~cm}$ of height) with cooling attached at the bottom of the pyrolyzer. The cooling is located at the bottom of the chimneys to condense the cracked gases, which then flow down through the chamber to form wood vinegar. A fourth chimney $(6 \mathrm{~cm}$ in diameter and $18 \mathrm{~cm}$ of height, fixed on lid) is located at the top of the pyrolyzer and it provides an outlet for initial white smoke and is closed after yellowish and acrid smoke appears.

\section{The Production of Charcoal and Wood Vinegar}

The banana peel and banana bunch were air dried. The dried banana peel and banana bunch were carbonized at $350^{\circ} \mathrm{C}$ in a 200 -liter-vertical-oil-drum kiln for 1 day. The temperature was measured by thermocouple (Hioki 3441-02 K Type Thermocouple Temperature HiTester) located in the combustion zone. The charcoal and wood vinegar were collected and the percent yield was calculated.

After installation $15-20 \mathrm{~kg}$ of banana peel or banana bunch was loaded in the pyrolyzer and was pre-heated to drive the cool air in the pyrolyzer out and to dehydrate the raw material until the smoke turned white (Fig. 1a). Then, the material was allowed to burn further until the temperature increased up to $350^{\circ} \mathrm{C}$.

During pyrolyzer operation, the bottom door is propped open until the fire is self-sustaining, at which point it is closed and all possible cracks are blocked with clay to restrict the levels of oxygen inside so as to create environment favorable for the pyrolysis. It is also necessary to cover the kiln completely by placing a lid at the top chimney (Fig. 1b). During pyrolysis, charcoal, as well as liquids and gasses are produced. The smoke was condensed to wood vinegar by flow through the three cooling chimneys. The production of raw wood vinegar is finished when the droplets turn black, indicating that tar had formed (Burnette, 2010).

After the carbonization process, the pyrolyzer was allowed to cool to atmosphere temperature for 1 day. Then, charcoal and wood vinegar were collected and measured to calculate the percent yield.

\section{Characterization of Charcoal}

Charcoals were characterized by FTIR (GX, Perkin Elmer) and SEM (LEO 1455 VP). The proximate analysis was also used for ash content (ASTM, 1996a), volatile matter (ASTM, 1996b) and fixed carbon (ASTM, 1994) determination in dried weight.

\section{Charcoal Briquettes Production}

After carbonization for 1 day, the kiln is then left to cool until it is safe to touch the exterior. After the kiln has cooled, the charcoal can be harvested and ground to fine powder. Various ratios of banana peel charcoal, or banana bunch charcoal, to clay (100:0, 95:5, 90:10 and 85:15) were used. The mixtures were wetted and blended with water. Moisture, in specific amounts, was reintroduced to the charcoal/clay mixture before pressing in order to increase briquette strength through capillary binding effects. The charcoal/clay mixture was then briquetted using a male/female roller configuration in a roller press briquetter with 7.5 horsepower motor, three-phase power, capacity of three tons per day (Fig. 2a). The charcoal briquette is cylindrical in shape $(4 \mathrm{~cm}$ in external diameter, $0.8 \mathrm{~cm}$ in internal diameter and $10 \mathrm{~cm}$ in length) (Fig. 2b). The briquettes were then dried in the sun for 7 days. 

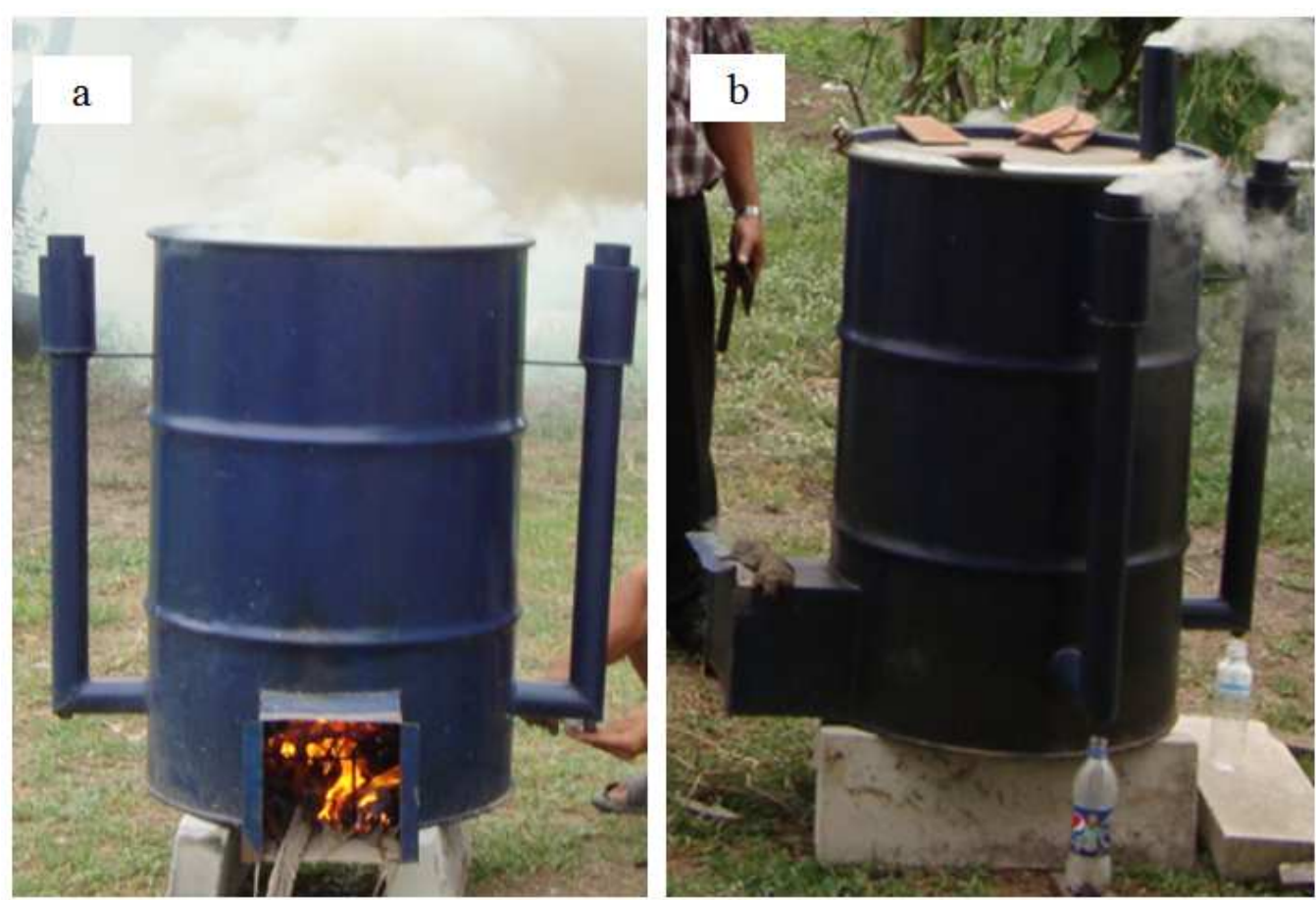

Fig. 1. The 200 L pyrolyzer during (a) ignition and (b) carbonization
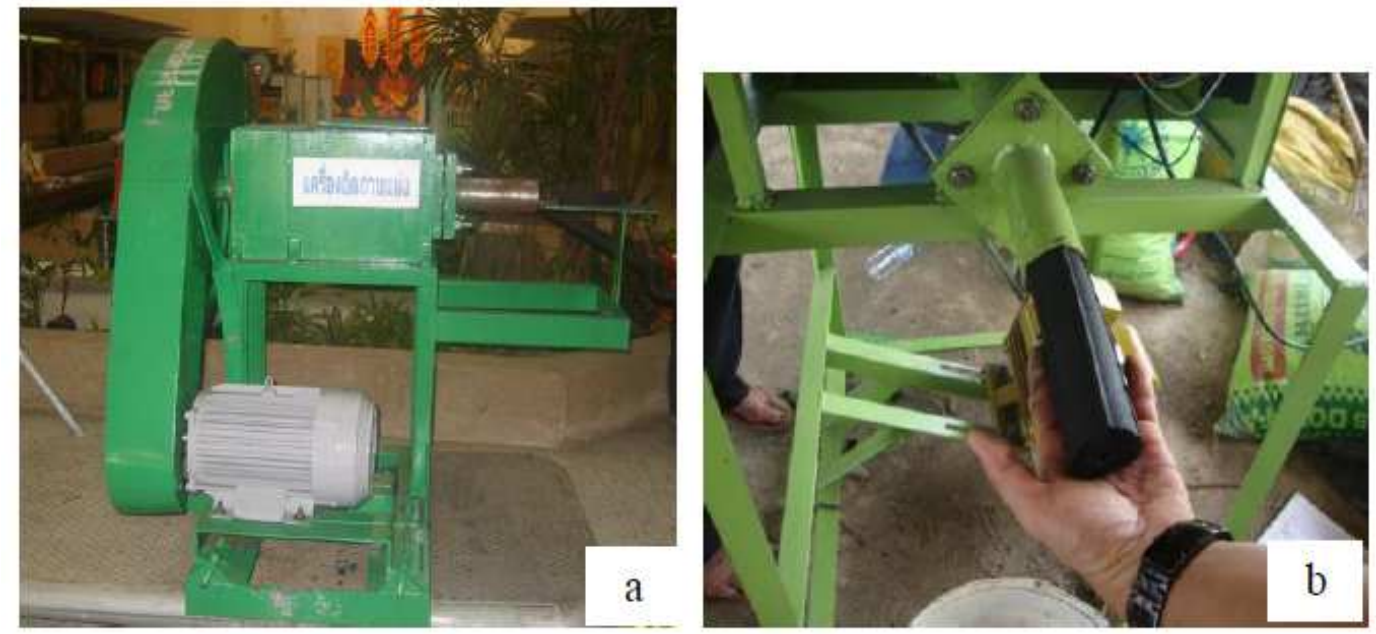

Fig. 2. The charcoal briquettes from a roller press briquetter with motor (a) briquetter (b) extruded charcoal

\section{Characterization of Charcoal Briquettes}

The ash content, calorific value, hardness, combustion calorific value, emissions data, burning time and combustion efficiency of charcoal briquettes were evaluated.

\section{The Calorific Value Determination}

For the determination of the calorific value the higher heating value was measured by an automatic bomb calorimeter (1108 Oxygen Combustion Bomb Parr).

\section{Hardness Measurement}

Hardness of the charcoal briquettes was determined by a tensile tester (Shimadzu Autograph, model AG-25TB). Tensile tester works by gradually increasing the pressure on the charcoal briquettes. The pressure is increased until the charcoal briquettes have been crashed, striked, or deformed. Press is simulated by the string principle. String has one end created by the tip, which is pressing on the charcoal briquettes. The resulting value is deduced from the pressure when charcoal briquettes have been crashed. 


\section{Emission, Burning time and Combustion Efficiency Analyses}

The Thai-bucket stove, which is used extensively throughout Thailand for cooking, was used for the testing of emissions, burning time and combustion efficiency. This stove is based on traditional ceramic designs. The stove has two main components, a galvanized iron bucket and an inner ceramic firebox. The stove is also insulated with cement plaster. The bucket is approximately $300 \mathrm{~mm}$ wide and $270 \mathrm{~mm}$ deep. It has an opening of $100 \times 50 \mathrm{~mm}$ cut into its side from the bottom, the inner ceramic firebox is $190 \mathrm{~mm}$ in diameter, holes of $20 \mathrm{~mm}$ in diameter are cut into the grates. Charcoal can be burnt on the grate. The fuels are normally ignited with kindling. Refueling is done by lifting the pot. The stove weighs about $10 \mathrm{~kg}$ (Bhattacharya et al., 2002).

\section{Emission Test}

The Thai-bucket stove to be tested was placed in the center of an indoor laboratory room. The emitted fumes were analyzed by dust detector (TISCH Air Environment Equipment) and CO analyzers (Gas Alert Micro 5). Dust detector and $\mathrm{CO}$ analyzers were placed $0.5 \mathrm{~m}$ from the stove. The charcoal briquette was ignited and after $5 \mathrm{~min}$ measurements of dust and $\mathrm{CO}$ were taken every $20 \mathrm{sec}$ for $15 \mathrm{~min}$. The flow rate was $1.17 \mathrm{~L} \mathrm{~s}^{-1}$.

\section{Burning Time and Efficiency Measurement}

The charcoal briquettes were weighted accurately and were tested for burning time and efficiency using the Thai-bucket stove. Efficiency is defined as the ratio of the energy entering the pot to the energy content of the fuel consumed. The distilled water boiling test is used for testing the efficiency of the stoves. A known quantity of distilled water is heated on the stove to achieve simmering. Water is brought to boil during the heating up phase and is maintained within $5^{\circ} \mathrm{C}$ of boiling point for $30 \mathrm{~min}$. There are problems associated with determining the individual efficiencies of both the heating up and simmering phases. This is because removal of combustibles at the end of the heating up phase is problematic. Thus, only the overall efficiency over the entire test period can be determined. After the amount of water evaporated is calculated, the remaining fuel is separated and weighed and the net amount of energy consumed is determined by the method of Bhattacharya et al. (2002). Effectively, this means the latent heat of water is included in the higher heating value. The higher heating value is calculated with water exiting the system in liquid form, while the latent heat value is calculated with the assumption that the water product leaves as vapour (Bhattacharya et al., 2002).

\section{Results and Discussion}

\section{The Production of Charcoal and Wood Vinegar}

\section{Percent Yield of Charcoal and Wood Vinegar}

The percent yield of charcoals and wood vinegars are shown in Table 1. It can be seen that the percent yield of charcoal from banana bunch is slightly higher than from banana peel. In turn there are lower yields of wood vinegar from banana bunch. Consequently, the content of volatile matter remains higher in banana bunch charcoal. This is because of the volatile matter from banana bunch is converted to wood vinegar during carbonization to a lower extent than from banana peel. Another reason for the lower wood vinegar yield from banana bunch may be due to low initial amounts of volatile compounds in banana bunch in comparison to banana peel. Thus banana bunch yields less wood vinegar. The value of fixed carbon in banana bunch charcoal is also higher than in banana peel charcoal. The ash content in banana peel charcoal tended to be higher than in banana bunch charcoal. This is because of the higher initial ash content in banana peel being higher than in banana bunch.

When comparing the results of this study to the production of wood vinegar from bark of Durio at pyrolysis temperature of $412^{\circ} \mathrm{C}$ it can be noticed that the published work reports percent yield in the range from 33.87 to $39.23 \%$ (Oramahi and Diba, 2013). The reason for the lower wood vinegar yield from both banana peel and banana bunch obtained in the current work may be due to the pyrolysis temperature $\left(350^{\circ} \mathrm{C}\right)$, which might be insufficient for complete pyrolysis to take place, thus yielding less wood vinegar product. Alternatively, the pyrolyzer used in this study may have low efficiency for condensation resulting in low yield of wood vinegar.

\section{Characterization of charcoal}

The FTIR spectrum of banana bunch charcoal (Fig. 3d) shows strong peaks of various functional groups, which are present to a lesser degree in the FTIR spectrum of banana peel charcoal (Fig. 3c). This indicates that banana bunch was pyrolysed to a lesser degree than banana peel. This assumption is further supported by the lower yield of wood vinegar from banana bunch than banana peel. The broad band at about $3400 \mathrm{~cm}^{-1}$ of both raw materials (Fig. 3a and b) corresponds to - $\mathrm{OH}$ stretching; this band is relates to specific intramolecular hydrogen bonds of cellulose (Tibolla et al., 2014). It represents the hydrophilicity of banana peel and banana bunch (Fig. $3 \mathrm{a}$ and b). However, the band at about $3400 \mathrm{~cm}^{-1}$ of both charcoals (Fig. 3c and d) corresponds to associated hydroxyl groups, which probably originate from the decomposition of phenolic hydroxyls (Cao et al., 2013). 
Table 1. Percent yield of charcoal and wood vinegar and proximate composition of charcoals from banana peel and banana bunch

\begin{tabular}{lcc}
\hline & Banana peel & Banana bunch \\
\hline \% Yield of Charcoal (weight/weight) & 57.00 & 58.60 \\
\% Yield of Wood vinegar (volume/weight) & 7.53 & 6.76 \\
\% Ash (dried weight) & 35.52 & 31.86 \\
\% Volatile matter (dried weight) & 28.31 & 29.21 \\
\% Fixed carbon (dried weight) & 36.17 & 38.93 \\
\hline
\end{tabular}



Fig. 3. Transmittance FTIR spectra of (a) banana peel (b) banana bunch (c) banana peel charcoal (d) banana bunch charcoal

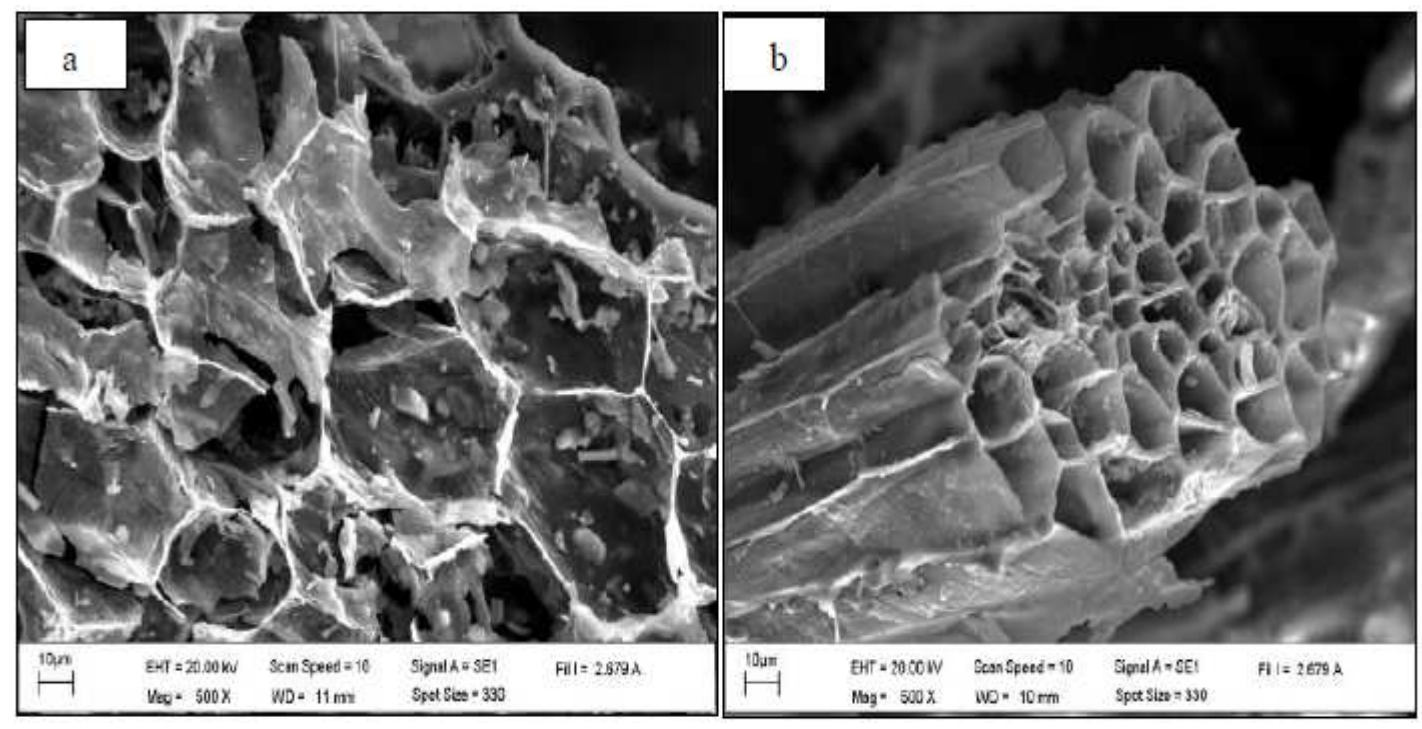

Fig. 4. SEM morphology of (a) banana peel charcoal (b) banana bunch charcoal

Both raw materials also displayed a small band in the region of $2923 \mathrm{~cm}^{-1}$, typical of the stretching vibrations of the $\mathrm{C}-\mathrm{H}$ bonds in hemicelluloses and cellulose (Elyounssi and Halim, 2014). This band was of lower intensity in the spectra of both charcoals. The very small band at $2351 \mathrm{~cm}^{-1}$ of both raw materials corresponds to $\mathrm{C}=\mathrm{O}$ vibrations of ketone groups of lignin (Zhao et al., 2014). It was observed that the band at $2351 \mathrm{~cm}^{-1}$ of banana bunch charcoal was also present (Fig. 3d). This suggests that the lignin in banana bunch was not completely carbonized at $350^{\circ} \mathrm{C}$. The broad band between 1700 and $1550 \mathrm{~cm}^{-1}$ in the spectrum of the raw materials corresponds to vibrations of the acetyl and uronic ester groups of hemicelluloses or to the ester linkages of carboxylic group of the ferulic and pcoumaric acids of lignin. It could also reveal that 
conjugated aromatic rings and conjugated carbonyl groups exist in the polyphenolic structure of lignin (Tibolla et al., 2014). These peaks almost completely disappeared after carbonization. However, the peak at about $1600 \mathrm{~cm}^{-1}$ still remained in the spectrum of banana bunch charcoal, which suggested that the sample contained lignin residues; i.e., carbonization did not remove lignin completely. This band is also refers to $\mathrm{C}=\mathrm{C}$ vibration originating from phenyl rings. It was suggested that the chains of phenyl rings can be transformed into polycondensated aromatic rings. (Cao et al., 2013). Indeed, the peaks assigned to the cellulose C-H groups stretching in the $1500-1200 \mathrm{~cm}^{-1}$ region disappeared after carbonization for both charcoals as compared with the raw materials. The band at 1050 $\mathrm{cm}^{-1}$ of both raw materials was assigned to associated hydrogen bonds in cellulose. The small peaks between $800-500 \mathrm{~cm}^{-1}$ in the spectra of the raw materials refer to typical cellulose structures and correspond to aromatic ring $\mathrm{C}-\mathrm{H}$ groups in the lignin (Tibolla et al., 2014). These peaks have also disappeared after carbonization for both charcoals, confirming the removal of lignin, hemicelluloses and celluloses. The peak at about 400$500 \mathrm{~cm}^{-1}$ found in the raw materials represents the $-\mathrm{C}$ C- stretching of cellulose (Chand et al., 2014). The broad band at about $900-1100 \mathrm{~cm}^{-1}$ found in the spectra of the charcoals represented aromatic $\mathrm{C}-\mathrm{H}$ bond bending. This indicates that macromolecular aromatic molecules began to rearrange (Cao et al., 2013). It also corresponds to $\mathrm{C}=\mathrm{O}$ stretching vibrations originating from partial oxidation of carbon by oxygen (Elyounssi and Halim, 2014). Finally, the band at about $500 \mathrm{~cm}^{-1}$ found in the charcoals corresponds to aliphatic $\mathrm{C}-\mathrm{C}$ vibrations (Cao et al., 2013). It indicates that the cellulose and lignin with aliphatic carbons remained in charcoals after pyrolysis at $350^{\circ} \mathrm{C}$.

Figure 4 shows the SEM morphology of banana peel charcoal (Fig. 4a) and banana bunch charcoal (Fig. 4b). It demonstrates that the structures of both charcoals are highly porously. Therefore, they have low density resulting in problems with handling and mechanical properties (Kusumaningrum and Munawar, 2014). Therefore, their density should be increased to improve these problems. However, the porosity of charcoals has advantages for the properties of the briquettes. The porous shapes of charcoals are honeycomb and tube structure in banana peel charcoal and banana bunch charcoal, respectively. These porous structures may be responsible for the increase in briquette strength through capillary binding of porous particles and mechanical interlocking of rough particle surfaces (Bazargan et al., 2014).

\section{Charcoal Briquettes Production}

Charcoal fines are materials totally lacking in plasticity and therefore need the addition of a sticking or agglomerating material to enable a briquette to be formed. A non-combustible binder that is effective at low concentrations may be suitable (Rousset et al., 2011). The banana peel charcoal and banana bunch charcoal show low density, which was augmented by a densification method for increasing density (Kusumaningrum and Munawar, 2014). In this process, clay was preferred as the binder. The mixtures have shown that clay improves plasticity and flowability of the mixtures. The flowability improvement provided by clay can be attributed to the fact that it reduces impact of friction forces on the contact male/female roller configuration in a roller press briquetter (Jezerska et al., 2014). The clay set through the loss of water, binding the banana peel charcoal and banana bunch charcoal into briquettes, which could be handled like ordinary lump charcoal in domestic stoves (Rousset et al., 2011).

\section{Characterization of Charcoal Briquettes}

\section{The Calorific Value of Charcoal Briquettes}

Table 2 shows the calorific value and proximate composition of banana peel charcoal briquettes and banana bunch charcoal briquettes with $0-15 \%$ clay. The calorific value of both charcoal briquettes decreased with increasing ratios of clay and ash content. This is because the carbon content has an influence on the calorific value of charcoal. Generally, the higher the carbon content is the higher the calorific yield (Yazdani et al., 2012). Furthermore, clay and ash are inorganic materials, which are stable and posses no calorific value. Therefore, it cannot be combusted and thus it cannot be converted into energy (Yazdani et al., 2012; Nuriana et al., 2014). However, calorific values of all briquettes remained higher than the Thai Industrial Standards Institute requirement of not less than 5,000 $\mathrm{cal} \mathrm{g}^{-1}$ (Prasityousil and Muenjina, 2013). It was observed that banana bunch charcoal briquettes have a higher calorific value than banana peel charcoal briquettes containing the same ratio of clay. This is because of banana bunch charcoal briquettes have a higher carbon content and lower ash than banana peel charcoal briquettes. As compared with sugar-cane bagasse fly ash briquettes with an average density of $1.12 \mathrm{~g} \mathrm{~cm}^{-3}$ and an average calorific value of $25,551 \mathrm{~kJ} \mathrm{~kg}^{-1}$ (Teixeira et al., 2010), both charcoal briquettes presented herein have a lower calorific value. This can be explained by the fact that both charcoal briquettes have low densities and the clay binder cannot be converted into energy.

\section{Hardness of Charcoal Briquettes}

The hardness properties of briquettes comprise resistances to crushing, impact, abrasion and water penetration (Richards, 1990). The hardness of 
briquettes was enhanced by increasing the interparticle contact area or by decreasing the inter-particle distance ( $\mathrm{Li}$ et al., 2012). The hardness of the briquettes is dependent on cohesion forces, which can be divided into true and apparent cohesion. Apparent cohesion is the force that keeps particles agglomerated by capillary forces and mechanical interlocking of rough particle surfaces. The apparent cohesion forces allow for deformation and agglomeration of the particles but are mostly lost upon drying. The true cohesion forces keep the particles together even after drying. These include electromagnetic and electrostatic forces of particles and cementing agents (Bazargan et al., 2014). The results of hardness properties for briquettes containing $5 \%(\mathrm{w} / \mathrm{w})$ of clay binder are presented in Table 3. Higher amounts of clay were not practical as briquettes with higher clay content were difficult to ignite. The banana bunch charcoal briquettes have higher hardness than the banana peel charcoal briquettes. They also give off lower amounts of dust, total CO but have lower burn time and combustion efficiency (Table 3). This is due to the fact that the banana bunch charcoal briquettes have more pore spaces and gaps than the banana peel charcoal briquettes (Fig. 4). In comparison with spruce sawdust briquettes, which were prepared with $5-20 \%$ starch binder (Jezerska et al., 2014), the banana bunch charcoal briquettes and the banana peel charcoal briquettes have lower hardness $(\geq 50 \mathrm{~kg})$. This was explained by the fact that the banana bunch charcoal briquettes and banana peel charcoal briquettes contain pore spaces and gaps, which can reduce the pellet resistance to deformation. This was confirmed from the SEM morphologies of both briquette types (Fig. 4), in which clear gaps and spaces were identified. During the hardness test, the existing gaps and spaces promote the relative movement of particles within the briquette matrix (Li et al., 2012), leading to the lower hardness for the banana bunch charcoal briquettes and banana peel charcoal briquettes. Ultimate strength of both charcoal briquettes with 5\% clay binder (Table 3) is lower than $3.8 \mathrm{~kg} \mathrm{~cm}^{-2}$ or $0.38 \mathrm{MPa}$ (Richard, 1990). Hence, they might break easily during transport or storage.

\section{Dust and CO Emissions from Charcoal Briquettes}

Addition of clay up to $5 \%(\mathrm{w} / \mathrm{w})$ results in briquettes that are relatively easy to ignite. Both charcoal briquettes containing $5 \%(\mathrm{w} / \mathrm{w})$ clay are smokeless during combustion and produce red-brown ash after combustion. The ash formed from the combustion of both briquettes still has the initial form of the briquettes. This result confirms the positive role of the clay binder on dust emission from charcoal briquettes during combustion.

The dust and $\mathrm{CO}$ emissions are related to the hardness of the briquettes. The higher hardness results in lower dust and $\mathrm{CO}$ emission. Consequently the banana bunch charcoal briquettes had lower dust and $\mathrm{CO}$ emissions than the banana peel charcoal briquettes (Table 3). Another important parameter is the fixed carbon content. Higher amounts of fixed carbon increase the probability of extensive combustion and more complete oxidation. This may be attributed to the higher kindling temperature of the briquettes, resulting in higher combustion and lower $\mathrm{CO}$ emissions. Therefore dust and CO emissions are low for briquettes with high amounts of fixed carbon. The average $\mathrm{CO}$ emission rate for banana bunch charcoal briquettes is lower than that for banana peel charcoal briquettes. This is likely due to higher carbon content resulting in more complete combustion. The increased fixed carbon content also results in shorter burning time.

Table 2. Proximate composition and calorific values of banana peel charcoal briquette and banana bunch charcoal briquette with differences ratios of clay

\begin{tabular}{llll}
\hline Samples & Ash \% & $\begin{array}{c}\text { Volatile } \\
\text { matter \% }\end{array}$ & $\begin{array}{c}\text { Fixed } \\
\text { carbon \% }\end{array}$ \\
\hline Banana peel charcoal briquette with 0\% clay & 32.52 & 28.30 & 39.17 \\
Banana peel charcoal briquette with 5\% clay & 35.39 & 26.88 & $3,989.55$ \\
Banana peel charcoal briquette with 10\% clay & 38.27 & 25.47 & 37.73 \\
Banana peel charcoal briquette with 15\% clay & 41.14 & 24.06 & 36.26 \\
Banana bunch charcoal briquette with 0\% clay & 28.86 & 29.21 & 34.80 \\
Banana bunch charcoal briquette with 5\% clay & 31.92 & 27.75 & 41.93 \\
Banana bunch charcoal briquette with 10\% clay & 34.97 & 26.30 & 40.33 \\
Banana bunch charcoal briquette with 15\% clay & 38.03 & 24.83 & 38.73 \\
\hline
\end{tabular}

Table 3. Hardness, ultimate strength, dust and CO emission, burn time and combustion efficiency of charcoal briquettes with $5 \%$ clay

\begin{tabular}{|c|c|c|c|c|c|c|c|}
\hline Samples & $\begin{array}{l}\text { Hardness } \\
(\mathrm{kg})\end{array}$ & $\begin{array}{l}\text { Ultimate } \\
\text { Strength }\left(\mathrm{kg} / \mathrm{cm}^{2}\right)\end{array}$ & $\begin{array}{l}\text { Dust } \\
\text { emission }\left(\mathrm{g} / \mathrm{m}^{3}\right)\end{array}$ & $\begin{array}{l}\text { Average CO } \\
\text { rate }(\mathrm{ppm} / \mathrm{s})\end{array}$ & $\begin{array}{l}\text { Total CO } \\
(\mathrm{ppm})\end{array}$ & $\begin{array}{l}\text { Burn time } \\
(\mathrm{min})\end{array}$ & $\begin{array}{l}\text { Combustion } \\
\text { efficiency }(\%)\end{array}$ \\
\hline Banana peel charcoal briquette & 23.31 & 2.00 & 15.38 & 3.76 & 3463 & 114 & 9.10 \\
\hline Banana bunch charcoal briquette & 25.90 & 2.26 & 11.97 & 1.72 & 1584 & 92 & 8.38 \\
\hline
\end{tabular}


The dust emissions from banana peel charcoal briquettes and banana bunch charcoal briquettes are 15.38 and $11.97 \mathrm{~g} \mathrm{~m}^{-3}$, respectively. These values are less than the levels set in the WHO guidelines for air quality with $50 \mathrm{\mu g} \mathrm{m}^{-3}$ for particle matter with size $<10$ $\mu \mathrm{m}$ and $25 \mu \mathrm{g} \mathrm{m}^{-3}$ for particle matter with size $<2.5 \mu \mathrm{m}$ (Fullerton et al., 2008).

The initial stage of $\mathrm{CO}$ release was probably due to the decarbonylation reaction of alkyl side-chains with carbonyl groups (-CO), while the increase of $\mathrm{CO}$ emission at high temperatures probably resulted from secondary reactions due to incomplete combustion of biomass (Cao et al., 2013). The decarbonylation reaction also results in the loss of oxygen bound to aromatic rings linked with the disappearance of phenolic and carboxylic carbons. The CO formation is attributed to decarbonylation reactions, specifically to the breakdown of $\mathrm{COC}$ and $\mathrm{C}=\mathrm{O}$ bonds, due to the decomposition of the ring-opened intermediates (Benstez-Guerrero et al., 2014). These results are demonstrated in the FTIR spectra of charcoal briquettes (Fig. 3c and d), which still have the $\mathrm{C}=\mathrm{O}$ functional groups (at $2351 \mathrm{~cm}^{-1}$ and at about $1600 \mathrm{~cm}^{-1}$ ).

Figure 5 presents the emission of $\mathrm{CO}$ of banana peel charcoal briquettes (Fig. 5a) and banana bunch charcoal briquettes (Fig. 5b) as a function of time. The $\mathrm{CO}$ emissions for both briquettes are not constant with time. This may be attributed to the effect of ash which forms during the combustion the ash hinders the flow of oxygen through to inner texture of the briquettes resulting in incomplete combustion and high $\mathrm{CO}$ emissions. However, at later stage oxygen flow through the briquettes is renewed resulting in reignition, more complete combustion and lower CO emissions (Huangfu et al., 2014). The CO emissions from banana peel charcoal briquettes are higher than that from banana bunch charcoal briquettes. The average rates of $\mathrm{CO}$ emission for banana peel charcoal briquettes and banana bunch charcoal briquettes are 3.76 and $1.72 \mathrm{ppm} \mathrm{s}^{-1}$, respectively, during the combustion period. This is due to the higher carbon content of banana bunch charcoal briquettes, which results in high temperature of fume gas and high oxidation of banana bunch charcoal briquettes during combustion. In comparison general wood and charcoal have $\mathrm{CO}$ emission in the range from $19-136 \mathrm{~g} \mathrm{~kg}^{-1}$ or $1.9-13.6 \%$ (Bhattacharya et al., 2002). The total CO emissions of the briquettes presented herein are much lower. Banana peel charcoal briquettes and banana bunch charcoal briquettes give total $\mathrm{CO}$ emissions of $3463 \mathrm{ppm}(0.35 \%)$ and $1568 \mathrm{ppm}(0.16 \%)$, respectively. It is also due to the high extent of oxidation or high combustion efficiency of these briquettes. It was concluded that gas mixtures of atmosphere with a low concentration of $\mathrm{CO}$, up to about $0.5 \%$, do not present any toxic threat to consumers as established by the International Standard for the Determination of Toxicity of Gases (Luo et al., 2002).
Burning Time and Combustion Efficiency of Charcoal Briquettes

\section{Burning Time and Water Temperature Measurements}

Figure 6 shows the relationship between the combustion time and water temperature during the combustion of the briquettes. It can be seen that the maximum temperatures of water reached are 88 and $84^{\circ} \mathrm{C}$ for banana peel charcoal briquettes and banana bunch charcoal briquettes, respectively. This is due to the lower kindling temperature of banana peel charcoal briquettes. It was observed that higher carbon content of briquettes results in higher temperature of fume gas, which leads to higher loss of energy out of the stove (Birzer et al., 2014). Therefore the maximum temperature of water reached with banana bunch charcoal briquettes combustion is lower than for banana peel charcoal briquettes combustion. A higher fixed carbon increases the calorific value and tends to increase the burning rate. Therefore, it is also affects the time needed to reach the maximum temperature of water. Thus, the time to reach the maximum temperature of water was 36 and 48 min for combustion of banana brunch charcoal briquettes and banana peel charcoal briquettes, respectively. In comparison, the time needed to reach the maximum water temperature with the combustion of wood pellets is 19.4-30.5 min (Huangfu et al., 2014). The banana peel and brunch charcoal briquettes release energy at a lower rate leading to the longer times required to boil water. Burning rate is an indicator of the intensity of the combustion i.e. the rate of the fuel burning affects the rate of energy being delivered (Huangfu et al., 2014). The higher burning rate thus results in shorter burning time. Therefore, the burning time of banana bunch charcoal briquettes is shorter than for banana bunch charcoal briquettes (Table 3).

\section{Combustion Efficiency}

Combustion efficiencies of banana peel charcoal briquettes and banana bunch charcoal briquettes were 9.10 and $8.38 \%$, respectively. It has been demonstrated by Birzer et al. (2014) that the temperature of fume gases affects the heat energy efficiency of stoves during the combustion process. The fume gas with higher temperature will result in higher energy loss from the stove and thus decrease the energy efficiency. In this research, the banana bunch charcoal briquettes contain higher amount of fixed carbon than banana peel charcoal briquettes. Therefore, the combustion of banana bunch charcoal briquettes leads to higher temperature of fume gases than for banana peel charcoal briquettes. The observed efficiency values fall in the efficiency range of $5-15 \%$ of traditional stoves in Asian countries (Bhattacharya et al., 2002). 




Fig. 5. The $\mathrm{CO}$ emission as function of time for (a) banana peel charcoal briquettes and (b) banana bunch charcoal briquettes



Fig. 6. Relationship between the time and water temperature during combustion of banana peel charcoal briquettes and banana bunch charcoal briquettes

\section{Conclusion}

Charcoal briquettes from banana peel and banana bunch were produced using $200 \mathrm{~L}$ pyrolyzer and conducting the pyrolysis at about $350{ }^{\circ} \mathrm{C}$. The yields of charcoal were 57.0 and $58.6 \% \mathrm{w} / \mathrm{w}$ for pyrolysis of banana peel and banana brunch, respectively. The yields of wood vinegar, on the other hand, were 7.53 and $6.76 \% \mathrm{w} / \mathrm{w}$ for banana peel and banana bunch respectively. These results present a low yield and indicate a low of the pyrolysis process as well as low condensation capacity of the pyrolyzer. The charcoal product from banana peel and banana bunch retained strong peaks of some functional groups. This result confirmed the incomplete pyrolysis of the charcoal products. The porous shapes of charcoals are honeycomb and tube structure in banana peel charcoal and banana bunch charcoal, respectively. These structures can help the hardness of the briquettes by employing capillary force and interlocking with the clay binder. The calorific value of both charcoal briquettes decreased with increasing ratios of clay and ash content. However, the calorific values of all briquettes with $0-15 \%$ of clay, which have values in the range from 5,115.51 to $6,396.66 \mathrm{cal} \mathrm{g}^{-1}$, are still higher than the Thai Industrial Standards Institute requirement of not less than 5,000 cal $\mathrm{g}^{-1}$. The hardness obtained with $5 \% \mathrm{w} / \mathrm{w}$ content of clay binder in banana peel charcoal briquettes and banana bunch charcoal briquettes is $23.31 \mathrm{~kg}$ and $25.90 \mathrm{~kg}$, respectively. Both charcoal briquettes prepared with $5 \%$ clay are smokeless while the combustion results in a redbrown ash. The dust emission, average CO 
concentrations, emission rate and total $\mathrm{CO}$ emission of banana peel charcoal briquettes and banana bunch

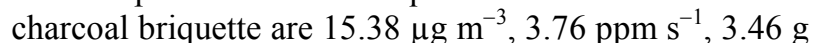
$\mathrm{kg}^{-1}$ and $11.97 \mu \mathrm{g} \mathrm{m}^{-3}, 1.72 \mathrm{ppm} \mathrm{s}^{-1}, 1.58 \mathrm{~g} \mathrm{~kg}^{-1}$, respectively. These values are less than the levels set in the WHO guidelines and the International Standard for the Determination of Toxicity of Gases. It was shown that the combustion of charcoal briquettes proceeds to a high level of completion. Combustion efficiencies of banana peel charcoal briquettes and banana bunch charcoal briquettes were 9.10 and $8.38 \%$, respectively. It was observed that the maximum temperatures of water are 88 and $84^{\circ} \mathrm{C}$ for banana peel charcoal briquettes and banana bunch charcoal briquettes, respectively. The time used to reach to maximum temperature during banana bunch charcoal briquette combustion (36 min) is shorter than for banana peel charcoal briquette combustion (48 min). The maximum burning times of 114 and $92 \mathrm{~min}$ were observed for banana peel and banana bunch charcoal briquettes, respectively. These results are a reflection of the composition of the charcoal materials (e.g., carbon and ash content) and clay binder. This research shows the possibility for improving the utilization of these charcoals by extrusion roller press briquetting along with utilization of clay binder to impart mechanical strength, limit $\mathrm{CO}$ and dust emissions and to modify burning time and combustion efficiency of the briquettes. These results can be considered a contribution to the development of more eco-friendly, sustainable and renewable utilization of banana waste.

\section{Acknowledgement}

The authors would like to thank staff of Chemistry Department and Faculty of Science, Naresuan University.

\section{Funding Information}

This research was supported by National Research Council of Thailand and partially supported by the Department of Chemistry and Faculty of Science, Naresuan University.

\section{Author's Contributions}

Sumrit Mopoung: Contribute in: (a) Experimental design, (b) discussion and conclusion of the results.

Vijitr Udeye: Contributed in: (a) The study of the related experiment, (b) protocol testing.

\section{Ethics}

The corresponding author states that this paper is original. Both authors have read the paper and approved of its content.

\section{References}

ASTM, 1994. Standard test method for fixed carbon in activate carbon. ASTM D 3172-89. American Standard of Testing Material.

ASTM, 1996a. Standard test method for total ash content of activate carbon. ASTM D 2866-94. American Standard of Testing Material.

ASTM, 1996b. Standard test method for volatile matter content of activate carbon. ASTM D 5832-95. American Standard of Testing Material.

Anwar, Z., M. Gulfraz and M. Irshad, 2014. Agroindustrial lignocellulosic biomass a key to unlock the future bio-energy: A brief review. J. Radiat. Res. Applied Sci., 7: 163-173.

DOI: 10.1016/j.jrras.2014.02.003

Bazargan, A., S.L. Rough and G. McKay, 2014. Compaction of palm kernel shell biochars for application as solid fuel. Biomass Bioenergy, 70: 489-497. DOI: 10.1016/j.biombioe.2014.08.015

Benstez-Guerrero, M., J. Ĺpez-Beceiro, P.E. SUnchezJiménez and J. Pascual-Cosp, 2014. Comparison of thermal behavior of natural and hot-washed sisal fibers based on their main components: Cellulose, xylan and lignin. TG-FTIR analysis of volatile products. Thermochimica Acta, 581: 70-86.

DOI: $10.1016 /$ j.tca.2014.02.013

Bhattacharya, S.C., D.O. Albina and P. Abdul Salam, 2002. Emission factors of wood and charcoal-fired cookstoves. Biomass. Bioenergy, 23: 453-469. DOI: 10.1016/S0961-9534(02)00072-7

Birzer, C., P. Medwell, G. MacFarlane, M. Read and J. Wilkey et al., 2014. A biochar-producing, dungburning cookstove for humanitarian purposes. Procedia Eng., 78: 243-249.

DOI: $10.1016 /$ j.proeng.2014.07.063

Burnette, R., 2010. An introduction to wood vinegar. ECHO Asia Notes, A Regional supplement to ECHO Development Notes.

Cao, J., G. Xiao, X. Xu, D. Shen and B. Jin, 2013. Study on carbonization of lignin by TG-FTIR and hightemperature carbonization reactor. Fuel Process. Technol., 106: 41-47.

DOI: 10.1016/j.fuproc.2012.06.016

Chand, P., A.K. Shil, M. Sharma and Y.B. Pakade, 2014. Improved adsorption of cadmium ions from aqueous solution using chemically modified apple pomace: Mechanism, kinetics and thermodynamics. Int. Biodeter. Biodegr., 90: 8-16. DOI: 10.1016/j.ibiod.2013.10.028

Claxton, L.D., 2014. The history, genotoxicity and carcinogenicity of carbon-based fuels and their emissions. Part 2: Solid fuels. Mutat. Res., 762: 108-122. DOI: 10.1016/j.mrrev.2014.07.002 
Demirbass, A., 1999. Properties of charcoal derived from hazelnut shell and the production of briquettes using pyrolytic oil. Energy, 24: 141-150.

DOI: $10.1016 / \mathrm{S} 0360-5442(98) 00077-2$

Elyounssi, K. and M. Halim, 2014. An investigation on the texture and microstructure of carbonized charcoals produced by two-step pyrolysis. J. Anal. Applied Pyrol., 109: 258-265.

DOI: $10.1016 /$ j.jaap.2014.06.003

Fullerton, D.G., N. Bruce and S.B. Gordon, 2008. Indoor air pollution from biomass fuel smoke is a major health concern in the developing world. T. R Soc. Tropl. Med. H., 102: 843-851. DOI: $10.1016 /$ j.trstmh.2008.05.028

Gladstone, S., V. Tersigni, J. Kennedy and J.A. Haldeman, 2014. Targeting briquetting as an alternative fuel source in Tanzania. Procedia Eng., 78: 287-291. DOI: 10.1016/j.proeng.2014.07.069

Huangfu, Y., H. Li, X. Chen, C. Xue and C. Chen et al., 2014. Effects of moisture content in fuel on thermal performance and emission of biomass semi-gasified cookstove. Energy Sustain. Dev., 21: 60-65.

DOI: 10.1016/j.esd.2014.05.007

Jezerska, L., O. Zajonc, J. Rozbroj, J. Vyletělek and J. Zegzulka, 2014. Research on effect of spruce sawdust with added starch on flowability and pelletization of the material. IERI Procedia, 8: 154-163. DOI: 10.1016/j.ieri.2014.09.026

Kusumaningrum, W.B. and S.S. Munawar, 2014. Prospect of bio-pellet as an alternative energy to substitute solid fuel based. Energy Procedia, 47: 303-309. DOI: 10.1016/j.egypro.2014.01.229

Li, H., X. Liu, R. Legros, X.T. Bi and C.J. Lim et al., 2012. Pelletization of torrefied sawdust and properties of torrefied pellets. Applied Energy, 93: 680-685. DOI: 10.1016/j.apenergy.2012.01.002

Luo, M., P. Roncalés, D. Djenane and J.A. Beltrun, 2000. Beef shelf life in low $\mathrm{O}_{2}$ and high $\mathrm{CO}_{2}$ atmospheres containing different low $\mathrm{CO}$ concentrations. Meat Sci., 55: 413-419. DOI: 10.1016/S0309-1740(99)00170-9

Massaro, M.M., S.F. Son and L.J. Groven, 2014. Mechanical, pyrolysis and combustion characterization of briquetted coal fines with Municipal Solid Waste plastic (MSW) binders. Fuel, 115: 62-69. DOI: 10.1016/j.fuel.2013.06.043

Mopoung, S., 2005. Chemical composition and physical properties of charcoal and activated charcoal from peel and bunch of banana. NU. Sci. J., 2: 107-119.

Mopoung, S., N. Sriprang and J. Namahoot, 2014. Sintered filter materials with controlled porosity for water purification prepared from mixtures with optimal ratio of zeolite, bentonite, kaolinite and charcoal. Applied Clay Sci., 88-89: 123-128.

DOI: $10.1016 /$ j.clay.2013.11.035
Mwampamba, T.H., M. Owen and M. Pigaht, 2013. Opportunities, challenges and way forward for the charcoal briquette industry in Sub-Saharan Africa. Energy Sustain. Dev., 17: 158-170. DOI: $10.1016 /$ j.esd.2012.10.006

Nathoa, C., U. Sirisukpoca and N. Pisutpaisal, 2014. Production of hydrogen and methane from banana peel by two phase anaerobic fermentation. Energy Procedia, 50: 702-710. DOI: $10.1016 /$ j.egypro.2014.06.086

Nuriana, W., N. Anisa and Martana, 2014. Synthesis preliminary studies durian peel bio briquettes as an alternative fuels. Energy Procedia, 47: 295-302. DOI: $10.1016 /$ j.egypro.2014.01.228

Onaji, P.B. and R.V. Siemons, 1993. Production of charcoal briquettes from cotton stalk in malawi: Methodology for feasibility studies using experiences in Sudan. Biomass Bioenergy, 4: 199-211. 10.1016/0961-9534(93)90059-D

Oramahi, H.A. and F. Diba, 2013. Maximizing the production of liquid smoke from bark of Durio by studying its potential compounds. Procedia Envir. Sci., 17: 60-69. DOI: 10.1016/j.proenv.2013.02.012

Prasityousil, J. and A. Muenjina, 2013. Properties of solid fuel briquettes produced from rejected material of municipal waste composting. Procedia Envir. Sci., 17: 603-610. DOI: $10.1016 /$ j.proenv.2013.02.076

Rao, F., F.J. Ramirez-Acosta, R.J. Sanchez-Leija, S. Song and A. Lopez-Valdivieso, 2011. Stability of kaolinite dispersions in the presence of sodium and aluminum ions. Applied Clay Sci., 51: 38-42. DOI: $10.1016 /$ j.clay.2010.10.023

Richards, S.R., 1990. Physical testing of fuel briquettes. Fuel Process. Technol., 25: 89-100. DOI: 10.1016/0378-3820(90)90098-D

Rousset, P., A. Caldeira-Pires, A. Sablowski and T. Rodrigues, 2011. LCA of eucalyptus wood charcoal briquettes. J. Clean. Prod., 19: 1647-1653. DOI: $10.1016 /$ j.jclepro.2011.05.015

Sjlie, H.K., 2012. Reducing greenhouse gas emissions from households and industry by the use of charcoal from sawmill residues in Tanzania. J. Clean. Prod., 27: 109-117. DOI: 10.1016/j.jclepro.2012.01.008

Teixeira, S.R., A.F.V. Pena and A.G. Miguel, 2010. Briquetting of charcoal from sugar-cane bagasse fly ash (scbfa) as an alternative fuel. Waste Manage., 30: 804-807. DOI: 10.1016/j.wasman.2010.01.018

Tibolla, H., F.M. Pelissari and F.C. Menegalli, 2014. Cellulose nanofibers produced from banana peel by chemical and enzymatic treatment. LWT-Food Sci. Technol., 59: 1311-1318. DOI: 10.1016/j.lwt.2014.04.011 
Yazdani, M.G., M. Hamizan and M.N. Shukur, 2012. Investigation of the fuel value and the environmental impact of selected wood samples gathered from Brunei Darussalam. Renew. Sust. Energ. Rev., 16: 4965-4969.

DOI: $10.1016 /$ j.rser.2012.04.025
Zhao, J., W. Xiuwen, J. Hu, Q. Liu and D. Shen et al., 2014. Thermal degradation of softwood lignin and hardwood lignin by TG-FTIR and Py-GC/MS. Polym. Degrad. Stabil., 108: 133-138.

DOI: 10.1016/j.polymdegradstab.2014.06.006 